\title{
Narrativa y ciencia. La importancia de las palabras en la investigación
}

\author{
Yolanda M. Guerra García
}

Recibido: 6 de julio de 2011 Revisado: 3 de septiembre de 2011 Aprobado: 24 de octubre de 2011

\section{RESUMEN}

El artículo analiza la importancia de saber narrar la ciencia de manera idónea y brinda algunos lineamientos para hacerlo. En un siglo invadido por la tecnología, donde el universo se encuentra al alcance de la mano con solamente un clic en Google o en cualquier otro buscador, pareciera como si cada vez más nos alejáramos de la necesidad de producir conocimiento nuevo, de pensar, repensar y de las técnicas de escribir esos pensamientos en un texto agradable de ser leído. Afortunadamente, hay excepciones frente a la era de copiar y pegar, y todavía se encuentran personas que logran escribir hermosamente, reflejando incluso en sus narraciones los hallazgos de su ciencia. En Colombia, ha comenzado la cultura de la investigación y de los cursos de tercer nivel; la que, vale aclarar, lleva siglos en otros países ${ }^{1}$. Este auge de investigación ha traído consigo la inmensa necesidad de escribir; no hay institución universitaria ni docente que se respete que no haga o deba hacer investigación y, a su vez, convertirse en multiplicador con los estudiantes, de la necesidad de escribir, investigar y de hacerlo apropiadamente. Allí es cuando el tema de la narrativa y la ciencia toma la mayor relevancia. Escribir, por paradójico que parezca, tiene su ciencia. ¿Cómo debe entonces narrarse la ciencia? ¿Es realmente fácil escribir? ¿Hay secretos? ¿Cuál debe ser la estructura de un texto científico? Esto es lo que se investiga y presenta en este artículo, que pretende ser un punto de partida más que de llegada al apasionante mundo de la narrativa y la ciencia.

\section{Palabras clave}

narrativa, ciencia, redacción, construcción de un texto escrito.

1 La cultura de las maestrías, los doctorados y postdoctorados y por supuesto, la cultura de la investigación que implica leer y escribir per se, lleva siglos en los así llamados países industrializados o del primer mundo. Estados Unidos, Inglaterra, Francia, Alemania, por nombrar solamente algunos de estos países, producen anualmente más de un millón de papers, que es como se le llama a los artículos publicados internacionalmente en los más importantes journals (revistas) del mundo. Colombia ha producido, en promedio, en un buen año, 84 papers. 


\title{
Narrative and science. The importance of words in the research process
}

\author{
Yolanda M. Guerra García
}

\begin{abstract}
The article analyzes the importance of knowing how to narrate the science in a suitable way, and offers some points to do so. In a century invaded by technology, where the universe is in our hands with only a click, in google or any other finder, it will seem as if we have moved away of the necessity to produce new knowledge, to think, re think and write with the necessary techniques those thoughts in a suitable text. Luckily, there are exceptions to the era of copying and pasting, and still there are people who manage to write, pleasantly, reflecting even in their narrations the findings of their science. In Colombia the culture of research and of the courses of third level has only begun, and has started the need to know how to write, to the point that there is no university or respected professor, that does not do or must make research as well as to become a multiplier of these with the students. The necessity to write, to research and to do it appropriately is what brings the importance of the subject of the narrative and science. Writing is a process that has especial techniques. How must then be narrated the science? How are the postgraduate programs in Colombia helping students to narrate their science? This is what this papers presents, intending to be only a starting point more than an arrival and final destination, to the exciting universe of narrative and science.
\end{abstract}

\section{Keywords}

Narrative, science, redaction, construction of a written text. 
Cada vez que escribo una palabra, Siento el latido del objeto encerrado por los signos.

Las oigo vivir.

Las palabras sacan las cosas del olvido y las ponen en el tiempo; sin ellas, desapare-

cerían.

Daniel Moyano²

\section{INTRODUCCIÓN}

La sociedad del conocimiento nos obliga a escribir cada vez más. Sin embargo, para los que no nacen con la pluma en el corazón, el acto de escribir puede convertirse en un episodio cercano a la pesadilla. Pocas han sido, a lo largo de mi existencia, las personas de las que puedo dar testimonio que se han gozado el inmenso placer de escribir y lo han hecho idóneamente. Entre ellas vale destacar a una persona, a la que he podido contemplar diariamente, durante más de un lustro, a menos de treinta centímetros de distancia en la Universidad Militar Nueva Granada. Alguien que escribe a diario y se goza este maravilloso oficio con la mayor sencillez, hablo del escritor y genio de la palabra, el maestro Fernando Soto Aparicio ${ }^{3}$.

2 Daniel Moyano es un importante escritor argentino, nacido en la hermosa ciudad de Córdoba. Ejerció toda su vida su doble pasión: la música y las letras. Estas últimas le costaron el exilio en España durante la dictadura militar de 1976. Murió en 1992, en España, después de haber dejado un hermoso legado de escritos que combinan la armonía de los compases de la música con la dicción y la más fina literatura. Entre sus obras relevantes se encuentran: Un silencio de corchea, Mi música es para esta gente, Dos golpes de timbal, del cual hace parte este epigrama, inspirado también en uno de los cursos del Post Doctorado que hoy nos ocupa y nos invita a escribir, impartido por el profesor Marcelo Casarín, docente investigador de la Universidad de Córdoba, Argentina, quien ilustró las clases de redacción del texto científico del Post Doctorado en Narrativa y Ciencia de la Universidad Santo Tomás.

3 Fernando Soto Aparicio, autor colombiano de más de sesenta novelas y tantos otros libros. Candidato varias veces al premio Nobel de Literatura. Maravillosa persona y excelente escritor de renombre in-
Ese placer de tener al lado un maestro que ha escrito más de sesenta novelas y obras clásicas de la literatura hispana me ha hecho sentir mejor persona y, de alguna manera, le ha dado calidad a mi vida. No porque me haya enseñado algo de narrativa o de literatura, sino porque ha hecho mi vida en general mucho mejor en todos los sentidos.

El maestro Fernando Soto Aparicio tiene una procesión diaria de personas que llegan hasta su pequeño escritorio a pedirle no solamente autógrafos y fotos, sino también consejos para escribir. Más de una vez he escuchado al maestro decir: “¡El día que a ustedes les toca escribir algo, se mueren! ¡Pero el día que yo no pueda escribir ni una sola palabra, ese día me muero!".

Escribir tiene dos marcadas tendencias: una como obligación y la otra como forma de vida. Si usted como lector pertenece a la primera tendencia (la de escribir por obligación, porque su trabajo de grado o tesis doctoral o cualquier otro ensayo le representan la entrada a la siguiente etapa de su proyecto de vida), entonces comparte con el 99\% de las personas del planeta la idea de que escribir es difícil.

Al final de estas líneas se espera que se haya roto ese paradigma, porque escribir es una verdadera delicia, casi comparable con la de leer, otra afición poco favorecida en Colombia, en comparación con Estados Unidos, donde el ciudadano promedio lee por lo menos 94 libros al año (excluyendo literatos, docentes, estudiantes y abogados). En Colombia se lee 0,5 (medio) libro al año, y la encuesta la realizó el Instituto Caro y

ternacional. El buscador Google le dio recientemente un premio por ser uno de los personajes que aparece más citado y con el mayor número de páginas en Internet. 
Cuervo en población estudiantil y universitaria, que se supone es la que está más expuesta a los libros durante la vida.

Leer un libro es establecer un diálogo animado por el deseo de comprender. Pero la comprensión no es posible si no existe un verdadero interés y tampoco si predomina una voracidad desesperada. Es indispensable una cierta serenidad de espíritu, una inteligencia enamorada y a la vez libre, que con calma y regusto avance por las líneas de cada página, gozando en el proceso de la intelección, de modo que sepa detenerse de vez en cuando a buscar la aclaración del sentido, a discutir o a reflexionar (Zubizarreta, 1969: 25).

\section{EL OFICIO DE NARRAR LA CIENCIA. LA ESCRITURA COMO PROFESIÓN}

En el homenaje que se le hizo en Cartagena a Gabriel García Márquez al cumplir sus ochenta años de vida, el Nobel dijo:

\begin{abstract}
No sé a qué horas sucedió todo. Sólo sé que desde que tenía 17 años y hasta la mañana de hoy no he hecho cosa distinta que levantarme temprano todos los días, sentarme frente a un teclado para llenar una página en blanco o una pantalla vacía del computador, con la única misión de escribir una historia aún no contada por nadie, que le haga más feliz la vida a un lector inexistente (García Márquez, 2007: 2-5).
\end{abstract}

Lo primero que se aprecia de la frase del Nobel es que escribir requiere como primera medida disciplina y constancia. En un mundo plagado de entretenimiento de toda índole (televisión, Internet, videojuegos, música, blackberries, Ipods, MP3 y otras "delicias"), sucumbir ante la tentación de hacer algo diferente a escribir es muy fácil. Pero para aquellos que aman escribir o como en el caso del lector, tienen que escribir, el primer consejo es la autodisciplina. Hay que imponerse un horario y procurar que diariamente, ojala a la misma hora se escriba por lo menos una línea, si es posible un párrafo.

Los investigadores, profesores, estudiantes y en general todas las personas que están obligadas a redactar un documento de cierta calidad, deben imponerse esta regla de oro: sacar tiempo diario para escribir. Por ejemplo, es sorprendente para mí ver a los jóvenes de hoy en día emplear tiempo valioso de sus vidas, incluso varias horas del día, dedicados a actualizar su página en redes sociales como Facebook, Myspace, y tantas otras. Yo lo considero una pérdida de tiempo total, es como llevar un libro diario en público, nada menos que en Internet, relevante para el ego si lo que deseamos es expandirlo, pero peligroso para lo que constituye la delicia de la vida privada. No obstante, si lo vemos por el lado del ejercicio aquel que podría preparar a los jóvenes para escribir en el futuro asuntos dignos de ser leídos, podría ser parcialmente rescatable. A escribir se aprende escribiendo y es un buen ejercicio comenzar con un diario. Después de todo, los diarios de observación son una de las técnicas de investigación más valiosas que existen cuando se realizan trabajos de campo. Hay profesiones, ciencias e investigaciones que permiten con mayor facilidad que otras realizarlos.

La Universidad Nacional Autónoma de México tiene un interesante documento (Pérez, 2010) sobre cómo deben operar los científicos cuando tratan de explicar los resultados de la historia, esos eventos desordenados y complejos que pueden ocurrir 
quizás solo una vez en toda su gloria. $\mathrm{Mu}$ chos dominios de la naturaleza -cosmología, geología y evolución entre ellas- deben ser estudiados con las herramientas de la lógica. Los métodos apropiados se enfocan en la narrativa y no en el experimento, como se concibe usualmente.

Este artículo trae a colación el estudio que hiciere el investigador Stephen Gould (1989: 100) sobre la forma como se conecta la narrativa y la ciencia. En muchas ciencias solo se pueden "contar cuentos" porque los sucesos son contingentes, únicos e impredecibles, afirma Gould. Los experimentos son irrelevantes en la evolución o en la paleontología porque nada es reproducible. La historia, incluyendo la de la evolución, no es más que "una simple cosa después de otra". Podemos explicar lo que pasó, pero no podemos predecir lo que va a pasar en el futuro. Tradicionalmente, las ciencias se han agrupado en dos categorías: las ciencias duras, en las que eventos repetibles pueden predecirse a partir de un formalismo matemático que expresa las leyes de la naturaleza; y las ciencias blandas, en las cuales, debido a su inherente variabilidad, solo es posible dar una explicación narrada expo facto, es decir, después del hecho, de eventos distinguibles. A la primera categoría pertenecen la física, la química y la biología molecular; la evolución biológica y la economía pertenecen a la segunda.

La investigación narrativa se utiliza cada vez más en estudios sobre la experiencia educativa. Tiene una larga historia tanto dentro como fuera de la educación. Según Connelly y Clandinin (1995), la razón principal para el uso de la narrativa en la investigación educativa es que los seres humanos somos organismos contadores de historias, organismos que, individual y socialmente, tenemos vidas relatadas.

\section{LA IMPORTANCIA DE ESCRIBIR}

Hay que entender a la escritura como una tecnología, como una herramienta: es un instrumento que sirve a la humanidad para resolver problemas. De una parte, permite registrar información y darle permanencia en el tiempo. La escritura extiende la memoria humana, "amplía" la capacidad del cerebro (reservorio corporal de la memoria). Y esto ocurre a nivel de cada individuo alfabetizado y también para la humanidad, cuya memoria colectiva abarca el conjunto de bibliotecas y archivos del mundo. De otra parte, la escritura (en cuanto medio de comunicación) posibilita contactarse con otros que no están físicamente presentes, extiende los límites espaciales de la comunicación. La escritura achica las distancias físicas (Carlino, 2005).

La UNESCO (1983) ha sentenciado que:

[...] la finalidad esencial de un artículo científico es comunicar los resultados de investigaciones, ideas y debates de una manera clara, concisa y fidedigna; la publicación es uno de los métodos inherentes al trabajo científico. Es preciso establecer estrategias de publicación bien elaboradas y seguir con conocimiento de causa una serie de normas adecuadas para facilitar el intercambio entre científicos de todos los países y reducir a proporciones razonables el incremento del volumen de publicaciones.

Según Leticia Artiles Visbal (1995), cuando se trata el tema del artículo científico es ineludible declarar el nexo que lo une con el proceso de investigación. Lo que se investiga y no se escribe, o se escribe y no 
se publica, equivale a no haber hecho nada, a jamás haber investigado. En tal caso, se pierde la consistencia en el tiempo y el caudal de información de investigadores y colectivos científicos.

Es poco probable que de una investigación con deficiencias metodológicas se pueda escribir un buen artículo. Resulta poco frecuente que una revista científica rechace un artículo por problemas formales, pues estos tienen arreglo; lo importante, trascendente e irreversible son los problemas de contenido y estos últimos son causados, generalmente, por un mal diseño experimental. Pero una buena investigación puede no conducir a un buen artículo si no se conoce el modo adecuado de elaborarlo. Un artículo mal redactado puede dar al traste con el resultado de una buena investigación, si no está bien presentado.

\section{EL DISCURSO Y LA NARRATIVA}

La narrativa es una forma discursiva, es decir, se comprende a partir del discurso y su relación con el lenguaje. Los analistas del discurso intentan ir más allá de definiciones características del sentido común. Admiten que el discurso es una forma de uso del lenguaje (Meza, 2008). No obstante, puesto que esta última definición continúa siendo imprecisa y no siempre conveniente, introduce un concepto de "discurso" más teórico, a la vez que más específico y más amplio en sus aplicaciones. Se pretende incluir otros componentes esenciales en este nuevo concepto; a saber, quién utiliza el lenguaje, cómo lo utiliza, por qué y cuándo lo hace (Van Dijk, 2000: 22). Batini (2000: 6) dice que el hombre moderno tiene necesidad de narraciones porque en la narración reencuentra espacio y tiempo para la propia vida. Más aún, como la posmo- dernidad está poniendo en tela de juicio un desarrollo tecnológico y científico indiscriminado que ha olvidado completamente el desarrollo humano, hay una emergencia del sujeto, de hombres y mujeres que son en sus circunstancias particulares. Dicho con otras palabras: "A nivel mundial, las sociedades se encuentran en un momento de replanteamiento, en una búsqueda de cambio de era conceptual, que equivaldría a la necesidad urgente de establecer un nuevo contrato natural y humano" (Martínez, 1997: 7).

Hablando propiamente del discurso, Ricoeur (1985: 48) señaló cuatro rasgos:

- El discurso se realiza siempre temporalmente y en un presente, mientras que el sistema del lenguaje es virtual y se halla fuera de tiempo. Esto es llamado la "instancia del discurso".

- En tanto que el lenguaje carece de sujeto -en el sentido de que la pregunta “quién está hablando?” no es pertinente-, el discurso se retrotrae a quien lo pronuncia por medio de un complejo haz de indicadores, tales como los pronombres personales. La "instancia del discurso" es autorreferencial.

- Mientras que en el lenguaje los signos solo se refieren a otros signos en el marco del mismo sistema, y en tanto que el lenguaje, como consecuencia, carece de un mundo, del mismo modo que carece de temporalidad y subjetividad, el discurso es siempre acerca de algo. Se refiere a un mundo que afirma describir, expresar o representar. En el discurso se actualiza la función simbólica del lenguaje. 
- Por último, según Ricouer (1985), en tanto que el lenguaje es solo la condición para la comunicación, para la cual provee los códigos, todos los mensajes se intercambian en el lenguaje. En este sentido, el discurso no tiene únicamente un mundo, sino otro, otra persona, un interlocutor al cual está dirigido.

\section{El eNREDo DE TENER QUE ESCRIBIR}

Las principales inquietudes que tienen los estudiantes tanto de pregrado como de posgrado, e incluso los profesionales egresados o en ejercicio, tienen que ver con la elaboración y redacción de textos formales para diversos fines: informes, ensayos, resúmenes ejecutivos, artículos, capítulos de libros, etc. En fin, son muchos los textos que en cualquier momento pueden poner en serios problemas a un estudiante en cualquier escenario en el que interviene, y más si este no cuenta con las herramientas necesarias para la estructuración adecuada de un texto en el cual pueda expresar sus ideas, argumentar sus posiciones, proponer alternativas o justificar resultados.

Preguntas tales como: ¿cómo puedo hacer un ensayo?, ¿estará bien lo que he acabado de escribir?, ¿cómo mejorar lo que escribo?, son frecuentemente formuladas por los estudiantes en procura de buscar soluciones a sus inmediatos inconvenientes. Por esta razón, las respuestas a estas preguntas vienen dadas no solamente por la capacidad del docente de guiar al estudiante hacia la formulación de un texto que cumpla con sus propias expectativas, brindándole métodos y herramientas, ya sean libros, artículos, elementos memorísticos, entre otros, sino también su función deberá estar orientada a la motivación del estudiante en torno a la escritura, pero antes que esto es importante crear una "pasión" por la lectura.

Por esta razón, Noguera (2005) sostiene que para aprender a escribir primero hay que aprender a leer, por lo cual es fundamental que desde el inicio se explore toda esa capacidad creativa del ser humano desde su infancia a través de la lectura, de manera que en la adultez puedan concretar de forma correcta sus ideas. Así mismo, afirma que dentro de las deficiencias del sistema educativo se encuentra que a los jóvenes estudiantes se les "enseña a redactar", se les brindan herramientas que simplemente indican unos procesos que debe seguir, unos criterios de presentación que no les permiten descubrir sus fortalezas de escritura ni crear su propio estilo. Por tal motivo, "el enfoque es más práctico que literario, ya que solo estos mecanismos sirven ${ }^{4}$ para que los futuros profesionales sepan comunicarse por escrito con cierta precisión" (p. 9).

\section{LA COMPRENSIÓN DE LECTURA COMO PROBLEMA}

Como se afirmó, el problema fundamental en el proceso de escritura tiene como antecedente la lectura, es decir, que el sujeto sea capaz de abordar un texto, de poderlo desarticular en sus partes esenciales, de manera que pueda comprenderlo y captar su mensaje, lograr obtener la idea fundamental del escrito que está interpretando.

Desde esta perspectiva podría afirmarse que la educación primaria ha realizado de manera incompleta una de las tareas primordiales que la sociedad le encomendara: puso los cimientos al

4 En inglés, la palabra buscar es search, investigación se escribe research, re-buscar. En francés también buscar significa cherche e investigación recherche. En español, investigar viene de la palabra en latín in-vestigium-ire, ir en busca de la verdad. 
promover que el alumno sea capaz de decodificar los signos escritos, pero al no propiciar que el educando adquiera estrategias que le permitan desentrañar y comprender el significado de los textos su obra queda inconclusa (Ramos Maldonado, 2005: 15).

Es evidente cómo esta problemática de la lectura ha sido planteada por diferentes autoridades en el mundo como un aspecto fundamental para la calidad educativa: "Adler, en Estados Unidos de América, hizo alusión a la negligencia casi total en que se ha tenido a la lectura inteligente a lo largo del sistema escolar" (p. 16), por lo cual la comprensión de lectura es un aspecto de suma importancia en la elaboración de textos o escritos de cualquier tipo.

\section{Generación de IDEAS}

Todo proceso de generación de ideas implica también un complejo proceso de recolección de información. Por tanto, esto último tiene una gran importancia para el desarrollo del marco teórico que constituirá el contenido del texto.

Al respecto, Serafini (1989) establece dos fases en la composición del escrito: la producción o generación de ideas y la producción del texto final.

\section{Producción de ideas}

Para poder elaborar un texto es necesario hacer un plan de trabajo que permita establecer la ruta de acción, es decir, hacia dónde queremos ir y qué pretendemos conseguir al finalizar el trabajo; por lo cual, este principio también aplica para la recolección de la información preliminar que servirá de base para el contenido del texto. Es importante tener una idea precisa de lo que estamos buscando antes de emprender la búsqueda, por lo que se sugiere diseñar una lista de puntos que clarifiquen la recolección de información (Serafini, 1989: 38).

El siguiente paso será entonces categorizar la información que hemos logrado recolectar. Para alcanzar este objetivo podemos acudir a diferentes mecanismos técnicos como el "agrupamiento asociativo", que permite trasladar sobre el papel un conjunto de ideas asociadas. Este agrupamiento asociativo, planteado por Serafini (1989), responde en sus principios al método desarrollado por Tony Buzan en su texto El libro de los mapas mentales de 1996. Este método se fundamenta en el desarrollo de una palabra clave o tema central a través de ramificaciones de sub-conceptos que tienen diferentes niveles de asociación con el tema. A su vez, de cada ramificación que se vincula al tema central se van derivando nuevas asociaciones que desarrollan conceptos íntimamente relacionados con los subconceptos, y por ende con la temática central. El propósito final es "desarticular" el concepto clave en expresiones más simples.

Por último, Serafini (1989: 50-53) plantea que la determinación de la tesis y el punto de vista del autor permiten completar la fase de orientación de la información recolectada. Con la tesis se establece una formalidad en las relaciones de las diferentes categorías estableciendo procesos de causalidad-efecto, y con el punto de vista del autor se establece la perspectiva desde la cual parte la construcción de los hechos y las valoraciones que este determine frente al fenómeno.

De igual forma, en este proceso de producción de ideas podemos acudir a lo planteado por Álvaro Díaz (1999), en lo que él 
llama fase de invención o fase pre-escritural en el proceso de composición.

En esta etapa, el escritor empieza el descubrimiento de las ideas sobre las cuales se desarrollará el tema que trabajará. Inicia entonces un proceso que involucra una compleja operación de raciocinio y asociación epistemológica “...pensar, responder interrogantes, eliminar ideas, descartar posibilidades, reorganizar, cambiar de ideas... y seguir pensando" (p. 75).

En ese orden de ideas, se puede establecer que esta es la etapa más crítica del proceso de elaboración de un texto, ya que si bien el sujeto tiene una gran cantidad de ideas, conceptos, problemáticas y deseos, estos se encuentran totalmente dispersos y ese es el momento en el cual el escritor deberá enfocar su objeto de estudio; es decir, deberá darle una orientación al tema o propuesta que desea abordar.

Desde el punto de vista pedagógico, el gran reto de los docentes es saber orientar al alumno, tratando de descubrir sus intereses y expectativas frente al trabajo de investigación, por lo cual es importante que desde la labor académica se brinden las herramientas necesarias para que los estudiantes descubran sus potencialidades y sus áreas de interés. Esta estrategia mejorará sustancialmente su desempeño y la calidad en los resultados en los trabajos que les sean asignados.

\section{Mecanismos Para La GENERACIÓN DE IDEAS}

\section{Brainstorming}

El Brainstorming o lluvia de ideas es una técnica creada en el año 1941 por Alex Osbor- ne. Su carácter es de aplicación grupal para la generación de ideas originales. Potencia la invención de nuevas alternativas de solución a problemas propuestos mediante el aprovechamiento de la capacidad creativa de los miembros del grupo: "Por su carácter exploratorio, se puede utilizar en las primeras etapas de una investigación. También se utiliza en combinación con otras técnicas, por ejemplo, para iniciar una discusión grupal, y constituye la primera fase de un grupo nominal" (Vázquez y Ferreira Da Silva, 2006: 75).

\section{Grupos nominales}

Gómez Fraile, Vilar y Tejero (2003) proponen otra técnica denominada grupo nominal. Esta es una técnica grupal que consiste en la generación de ideas abordando un caso de análisis específico. Consta de dos fases: primero se reúnen todos los miembros del equipo y escriben la mayor cantidad de ideas que se les vienen a la mente y luego viene el registro y discusión de las ideas generadas, a fin de evaluarlas, jerarquizarlas y seleccionar las más idóneas para la resolución del caso.

\section{Diagrama causa - efecto}

En investigación hay una idea fundamental que es la de buscar soluciones a problemas planteados por el investigador. De hecho, la palabra "investigación" en todos los lenguajes significa búsqueda de soluciones. Estas soluciones pueden evidenciarse en la demostración de la hipótesis, si es en el enfoque de la investigación empírico-analítica, o también en la verificación y asociación de ideas, discursos, conceptos, imágenes y demás representaciones para la construcción de nuevas teorías o formulaciones, como es 
el caso de la investigación histórico-hermenéutica. En todo caso, el investigador deberá tratar de encontrar las alternativas que brinden una respuesta concreta, por lo cual deberá recurrir a unos antecedentes del problema al que se ve enfrentado.

De acuerdo con esto el diagrama causa efecto, también conocido como diagrama de espina de pescado, es una excelente herramienta para la identificación de las causas que preceden a los fenómenos estudiados, con el fin de llegar a elaborar conexiones que le permitan al investigador vislumbrar esas alternativas de solución necesarias para dar explicación al problema.

El diagrama de espina de pescado es un “diagrama usado para organizar y demostrar visualmente las causas posibles de un problema o circunstancia; también llamado diagrama causa-efecto o diagrama de Ishikawa" (Finch Stoner, Freeman, Gilbert y Mascaró Sacristán, 1996: 244).

\section{Proyección tecnológica}

Por su parte, John O'Shaughnessy (1991), desde la perspectiva de la investigación en mercadeo, propone un método para la generación de ideas que puede ser aplicado en diferentes contextos, denominado el método de proyecciones tecnológicas, que tiene como objetivo la anticipación de fenómenos o avances dentro de un campo específico o la proyección de fenómenos futuros de acuerdo con unas variables establecidas. Por su carácter multidisciplinario, requiere del aporte de profesionales de diversas áreas que permitan configurar propuestas exitosas (p. 280).

\section{LA FORMULACIÓN DE INTERROGANTES}

Otro de los métodos que pueden facilitar este proceso consiste en la generación de ideas a partir de interrogantes, método cuyos orígenes se remontan a la Grecia Antigua en la figura de la mayéutica de Sócrates, precedida por un proceso irónico - refutativo (Reale y Antíseri, 2007: 178).

En el momento irónico se obligaba al interlocutor a dar cuenta de sí en todos los sentidos, contando con un componente de transformación multifuncional y variada cuyo objetivo era la generación de confusiones. En el segundo momento, el momento refutativo, se llevaba al interlocutor al límite haciendo evidente su ignorancia y poniendo al descubierto su aparente saber. La mayéutica se fundamenta en la idea del descubrimiento de la verdad, la cual se basa en el conocimiento que reposa en la conciencia del individuo.

\section{Mapas mentales}

En el año de 1974, con el libro Use your head, Tony Buzan da origen a un nuevo método de estudio que rompe con los esquemas lineales tradicionales de aprendizaje de una forma creativa y estimulante: el método de los mapas mentales. Esté método se basa en la graficación de un conjunto de conceptos, ideas, imágenes, palabras y otros elementos que se asocian alrededor de una palabra central.

El funcionamiento y representación gráfica de los mapas mentales se basa en el principio del pensamiento irradiante, el cual es ilustrado mediante dos analogías: el árbol como 
expresión de referencia gráfica y la neurona como referencia funcional.

En los mapas mentales, en una primera parte, el modelo del árbol se establece como la parte estructural en donde el tronco representa las ideas centrales o ideas principales, y las ramificaciones y hojas las ideas subordinadas o secundarias. Por lo cual, el mapa mental en su estructura "constituye un diseño del proceso comprensivo del aprendizaje, que se inicia en el descubrimiento de las ideas fundamentales y finaliza en las ideas secundarias y detalles" (Ontoria Peña y Gómez de Luque, 2002: 37).

En una segunda parte, se encuentra la analogía de la neurona. Como se sabe, una neurona está compuesta de un axón o conducto central y unas dendritas que se desprenden del núcleo radial de la misma. Es así como se asume que los mapas mentales se constituyen en esquemas de doble vía de información, receptores y trasmisores por medio de los cuales se desarrollan procesos asociativos y creativos para la generación de información y la construcción de nuevo conocimiento. Por tal razón, la neurona se constituye como parte funcional en el mapa mental, puesto que evidencia la trayectoria y la construcción del pensamiento desde un núcleo central hasta las ideas que se van a desarrollar (p. 37).

\section{ESTRUCTURA Y REDACCIÓN DEL TEXTO}

La forma como un texto puede mantener una coherencia en su contenido viene dada por el significado de las oraciones que le permiten que el escrito mantenga una estructura. Además de la coherencia semántica, un texto bien estructurado evidencia también unas relaciones contextuales en las cuales interactúan los sujetos y los objetos partícipes del fenómeno o tema desarrollado en el texto. La configuración de tal estructura (relaciones semánticas y relaciones conceptuales) facilita el abordaje y la lectura del texto (Viramonte de Ávalos, Peronard y Velásquez, 2000: 27-28).

La forma como se ordena un texto y el conjunto de asociaciones lógicas que están dispuestas dentro del contenido textual de un escrito permiten al lector la fácil identificación de los temas abordados. Marina Parra (1994) especifica que la estructura del texto configura tanto su orden global como su conjunto de relaciones jerárquicas, y que esta estructura tiene como objetivo determinar el orden de aparición de las categorías desarrolladas en el escrito.

En cuanto a las clases de estructuras, Parra (1994) sostiene lo siguiente: “Existen cuatro tipos de estructuras esquemáticas: narrativa, enunciativa, argumentativa y descriptiva. Estas estructuras pueden hacerse presentes en un mismo texto, pero de acuerdo con el tipo de texto prevalecen la una o la otra" (p. 110).

- Estructura narrativa: es empleada en textos como cuentos, leyendas, mitos, crónicas, anécdotas, actas, informes, entre otros escritos. Es aquella que permite al escritor expresar un sentido sobre la realidad. En esta estructura intervienen dos elementos: el actante y la acción. Estas estructuras constan de la siguiente composición: introducción, nudo y desenlace (pp. 111-112).

- Estructura enunciativa: en este tipo de estructura el objetivo es "hacer reaccionar al interlocutor". La información transmitida está ubicada desde un plano 
o contexto particular. La clasificación de la estructura enunciativa está constituida por tres categorías: un enunciado polémico, que revela la actitud del enunciador frente al destinatario, un enunciado situacional, que permite la ubicación del objeto que produce la información y un enunciado textual, que independiza el enunciado tanto del comunicante como del intérprete (pp. 116-117).

- Estructura argumentativa: es la estructura típica de los informes científicos y experimentales. Tiene como función la sustentación de afirmaciones con el propósito de persuadir o convencer al intérprete. Su composición se estructura en cuatro categorías, a saber: planteamiento del problema, formulación de hipótesis, demostración de la hipótesis y refutación o comprobación de la hipótesis. En la estructura argumentativa se expresan relaciones de causalidad, así como el uso de conjunciones y conectores se convierte en un elemento clave para la localización adecuada de las ideas (pp. 121-122).

- Estructura descriptiva: procura exponer al lector las situaciones de la forma más cercana a la realidad posible. Por su carácter, se puede definir en dos perspectivas: científica, cuando su propósito sea establecer o definir la funcionalidad de un objeto o proceso; y literaria, de carácter subjetivo. Con lo cual se puede decir que es la más estética de todas las estructuras, puesto que es frecuente el uso de figuras literarias como adjetivos, metáforas y símiles, los cuales permiten brindar elementos que puedan "embellecer" la lectura (pp. 124-125).

Parra afirma además que el lenguaje descriptivo tiene cuatro características: pre- cisión, con la cual se busca presentar realmente las cualidades del objeto observado; concisión, que permite darle rapidez y dinámica al texto; coherencia, que brinda la estructura lógica de las ideas expuestas a través de elementos conectores; y finalmente claridad, que facilita al lector el hacerse una idea casi real del objeto o proceso (p. 126).

Por otra parte, considerar el proceso de estructuración del texto como un asunto holístico puede tornarse una labor compleja. En este caso, según expertos lo recomendable es comenzar por la unidad del texto, es decir, por la palabra. Luego, pasar a la conjunción de palabras que tengan un verdadero sentido; dicho de otra forma, pasar a configurar frases. Después dichas frases deberán vincularse para conformar una unidad temática que estructure el siguiente nivel: un párrafo. Por último, la reunión de un conjunto de párrafos constituirá un capítulo, y una sumatoria de capítulos estructurarán, por último, un libro (Noguera, 2005: 21).

De acuerdo con lo anterior, el esquema para estructurar el contenido de un libro sería el siguiente:

\section{PALABRA - FRASE - PÁRRAFO - CAPÍTULO - LIBRO}

Otra forma de planificar la estructura lógica de un texto la expone Salazar (2004), quien demuestra una estrecha relación con el esquema que se desarrolló anteriormente e involucra tanto lo referente a la estructura del texto como lo relacionado con la redacción del mismo. Este método se fundamenta en la aplicación de las siguientes etapas de análisis textual. 


\section{Identificar la estructura interna y externa del texto}

\section{Estructura externa}

El análisis de la estructura externa de un texto busca que el lector identifique cuatro categorías dentro del escrito: el ordenamiento, que responde a un plan general de las partes del escrito; el lenguaje, que hace referencia a las formas como se debe brindar coherencia, cohesión, precisión y claridad del texto; el tono, que marca la intencionalidad que se le quiere dar al texto y que puede ser científico, crítico, argumentativo, persuasivo, etc.; y finalmente el estilo, con el cual se marca la manera expresiva que tendrá el texto que puede ser técnico, literario, filosófico, entre muchos otros (Salazar, 2004: 19).

\section{Estructura interna}

Básicamente, esta estructura indica la forma como se construirán los párrafos que harán parte del contenido o cuerpo del texto. Para este proceso se deberá establecer el objetivo del trabajo; en otras palabras, responder a la pregunta ¿para qué? Luego se identifica a quién va dirigido el texto. Después se debe discriminar el tema general y los temas específicos, para finalmente seleccionar y jerarquizar el material que hará parte del texto final (pp. 20-21).

\section{Redacción del texto}

\section{Estructuración temática}

El tercer paso que plantea el profesor Salazar (2004) es el proceso de construcción textual; es decir, la elaboración de la "radiografía textual" del escrito, la cual permite diseñar el esquema del texto desde lo general hacia lo particular. Este paso permite evitar la yuxtaposición o redundancia en el texto que pueda hacerlo complejo o que le quite la claridad necesaria para expresar eficazmente el tema propuesto.

En este orden de ideas, la radiografía textual se diseña siguiendo la secuencia que se expone a continuación: establecer un tema general; luego, con base en este, se establecen subdivisiones o subtemas, que en últimas vendrían a configurar cada uno de los párrafos del texto; y por último, se plantean unos mini-temas que vendrían siendo la estructura interna de los subtemas, es decir, las oraciones constitutivas de los párrafos del texto (p. 23).

\section{El PÁRRAFo COMO UNIDAD BÁSICA TEXTUAL}

Como se ha planteado hasta el momento, además de la palabra como unidad básica, el párrafo constituye la unidad formal superior para la estructuración de cualquier escrito. Por esta razón, se realizará un estudio de sus componentes, clasificación, estructura y forma de elaboración, a fin de tener claridad sobre su función frente a la correcta redacción de un escrito.

\section{Definición}

Para Díaz (1999), los párrafos son "bloques constituidos por una o varias oraciones que finalizan con punto y aparte; es decir, en un texto hay tantos párrafos como punto y aparte haya" (p. 45). Por su parte, Parra (1996) sostiene que el párrafo son "oraciones que se unen entre sí mediante elementos cohesivos y signos de puntuación y forman unidades superiores" (p. 93). 


\section{Estructura de los párrafos}

Los párrafos pueden estar organizados de acuerdo con la intención con la que se quiera expresar el contenido del texto. Por tanto, existe una relación directa entre la estructura del párrafo y el estilo que el autor quiera plasmar en el texto.

Por esta razón, los párrafos pueden ser desarrollados de tres formas: escritura con desarrollo de ejemplos, es decir, cuando el párrafo se apoya en ejemplos para exponer la idea; desarrollo por contraste, cuyo propósito es hacer evidentes similitudes entre los fenómenos; y por último, desarrollo del párrafo por encuadramiento, que permite guiar al lector a lo largo del texto (Serafini, 1989: 64-65).

\section{Características del párrafo}

Parra (1994) sostiene que para la construcción de un párrafo se deberán tener en cuenta tres aspectos: unidad, cohesión y extensión. Por unidad se entiende que cada párrafo deberá desarrollar una y solo una idea. La cohesión se logra mediante la aplicación de diferentes herramientas ortográficas, ya sean signos de puntuación o conectores lógicos, entre otros. La extensión tiene que ver, como se comentó anteriormente, con el enfoque que el autor quiera darle. Esta deberá ser acorde al desarrollo de la idea, por lo cual deberá mantener un equilibrio que evite la saturación o la superficialidad del tema desarrollado.

\section{Tipos de párrafos}

Existen párrafos que pueden tener como objetivo la estructuración o relación con otros párrafos dentro del texto. Por tal motivo, pueden establecerse párrafos de introducción, párrafos de transición o párrafos de finalización (Díaz, 1999: 53), y dentro de sus características se encuentra el continuo manejo de conectores lógicos, como por ejemplo: a continuación, a manera de resumen, en definitiva, etc.

Los párrafos de introducción tienen como objetivo hacer una presentación inicial del tema a fin de brindar al lector la idea sobre la cual tratará el tema. Por ejemplo:

El objetivo de este trabajo se centra en investigar la instrucción primaria de las mujeres en la sociedad de Santiago de Cuba de fines de siglo XVIII y principios del XIX. Para abordar esta temática se va a utilizar como eje del análisis la diferencia y diversidad de las experiencias femeninas en relación con la instrucción ${ }^{5}$.

Los párrafos de transición pueden presentarse como un breve resumen del contenido por desarrollar o como un planteamiento inicial de los temas por trabajar. Tienen como función brindar cohesión al texto $\mathrm{y}$ sirven como vínculos entre los párrafos de desarrollo o contenido. Un párrafo de transición puede ser:

A continuación se expondrán someramente algunos de los aspectos más importantes del pacto internacional de Derechos Civiles y Políticos que atañen a la privación de libertad. En primer lugar, y por lo que respecta a la vigencia de este Pacto en España, se ha de señalar que el mismo fue publicado en el BOE No 103...6.

5 Fragmento de ;Mujeres a la escuela! Lo que quería ser público y resultó privado. Santiago de Cuba a principios del Siglo XIX, de Lucía Provencio Garrigós.

6 Fragmento de La Impunidad de la Tortura y las obligaciones de los Estados en el Marco Internacional y Estatal, de Iñaki Rivera Beiras. 
Los párrafos de finalización indican el final del tema desarrollado. La extensión de este párrafo debe ser coherente con la extensión total del texto. De acuerdo con Díaz, para la correcta construcción de este párrafo se puede parafrasear la tesis, expresar comentarios, realizar una advertencia o anticipar un resultado o suceso. Por ejemplo:

En definitiva, y a manera de conclusión, estamos asistiendo en los últimos años a profundos cambios en la visión y el entendimiento mismo del derecho administrativo. Es necesario, sin embargo, afianzar el proceso iniciado a través de un significativo mejoramiento en la técnica normativa a utilizarse. Tal vez allí radique un factor fundamental para evitar que los logros alcanzados no ofrezcan los frutos deseados. Creo que es la asignatura pendiente sin perjuicio claro está de fortalecer la seguridad jurídica y la institucionalidad. Pero esa es materia que escapa a esas notas ${ }^{7}$.

\section{Presentación del texto}

No todos los textos escritos tienen la misma estructura; es decir, no pueden presentarse de la misma forma puesto que responden a diferentes necesidades y se escriben de acuerdo con objetivos particulares. De esta forma, se procederá a exponer algunas de las estructuras textuales más usadas tanto en el ámbito académico como en el campo profesional, a fin de tener una guía que permita la adecuada presentación de los textos para responder a cada demanda de información específica. Los textos científicos más utilizados en investigación son los siguientes.

\section{Informe}

Es un texto escrito en prosa científica, el cual tiene como propósito la solución de problemáticas, métodos y procedimientos por medio de los cuales se trata de hallar la solución al problema. En el informe el autor puede hacer una interpretación de los datos que está informando y de igual forma sustentar la obtención de dichos datos, por lo cual este texto tiene una marcada estructura argumentativa (Parra, 2004: 142).

Existen tres tipos de informe: informe expositivo, en el cual se narran hechos sin una interpretación del autor y se incluye una serie de antecedentes para la comprensión de los hechos narrados por el autor; informe interpretativo, que procura la interpretación y análisis de los hechos narrados; y el informe demostrativo, con el cual se plantea una tesis que se demuestra mediante la demostración de unos hechos y se establecen unas conclusiones finales (p. 143).

\section{Ensayo}

El ensayo es entendido como un escrito en prosa, generalmente breve, que expone con hondura, madurez y sensibilidad una interpretación personal sobre cualquier tema, sea filosófico, científico, histórico, literario, etc. No lo define el objeto sobre el cual se escribe sino la actitud del escritor ante el mismo; en el fondo, podría ser una hipótesis, una idea que se ensaya. El ensayo es producto de largas meditaciones y reflexiones, lo esencial es su sentido de exploración, su audacia y originalidad; es efecto de la aventura del pensamiento (Guerra, 2007).

\footnotetext{
7 Fragmento de Una visión del Derecho Administrativo en el Ecuador,
} de Jofre Campaña Mora. 


\section{Clases de ensayo}

El ensayo expositivo, como su nombre lo indica, expone ideas sobre un tema, presentando información alrededor del mismo y matizando esta información con la interpretación del autor y opiniones personales interesantes alrededor del tema en cuestión.

El ensayo argumentativo tiene como propósito defender una tesis con argumentos que pueden basarse en citas o referencias, datos concretos de experiencia investigativa, alusiones históricas, políticas u otras, fundamentos epistemológicos.

El ensayo crítico describe o analiza un hecho, fenómeno, obra o situación, emitiendo un juicio ponderado.

\section{Partes de un ensayo}

Introducción o planteamiento: es una de las partes fundamentales del ensayo para poder cautivar, atrapar o hechizar al lector. Se hace a partir de una opinión, pregunta o hipótesis

Desarrollo: tiene que ver con el proceso argumentativo de las ideas principales, secundarias y periféricas, las cuales acompañadas de citas, ejemplos, pruebas y registros lograrán sustentar la tesis principal del ensayo.

Conclusión: si al inicio del ensayo se presenta una tesis o hipótesis, es necesario desarrollarla para poderla comprobar o desaprobar a través del proceso argumentativo.

\section{Resumen}

Es un texto escrito basado en otro texto, el cual se reduce en su sentido formal respetando fundamentalmente el sentido del primero. No se ve reflejada la opinión del autor porque entonces dejaría de ser un resumen (Guerra, 2007).

Sus características son la fidelidad al texto original y la objetividad, ya que no se pueden expresar opiniones personales. El resumen requiere coherencia, originalidad y brevedad.

\section{Comentario}

Es un tipo de texto que consiste en la valoración o evaluación de un referente de la realidad o de un texto que se interpreta. $\mathrm{Al}$ igual que el resumen, es la construcción de un texto sobre otro texto pero con la inclusión de la opinión personal del autor y una evaluación que él mismo hace del texto original.

Entre las características del comenrario, es de anotar que si bien manifiesta una opinión, debe redactarse de manera impersonal (no "yo opino", sino, "se aprecia, por ejemplo"). Generalmente no se firma. Muestra un estilo claro, sencillo, con lenguaje preciso, oraciones cortas, párrafos breves. Los tipos de comentario son: informativo, interpretativo y argumentativo (Guerra, 2007).

\section{Reseña}

Es un texto escrito que se compone de un resumen y un comentario, ambos conjugados en un solo texto. La reseña se caracteriza por juzgar, evaluar y recomendar positiva o negativamente otro texto (Guerra, 2007). 


\section{Trabajo de grado}

Puede ir desde una pasantía, hasta el año de práctica o la realización de un estudio especial con créditos. Generalmente, se asocia con trabajo escrito y para esto se identifica con la monografía, la cual se definirá a continuación. Puede incluso considerarse como trabajo de grado un ensayo argumentativo, una pasantía o la elaboración de un informe de investigación (Guerra, 2007).

\section{Monografía}

De acuerdo con Icontec (2008), la monografía es una presentación formal del resultado de un proceso investigativo. Este trabajo requiere previa presentación de una propuesta, un anteproyecto y un proyecto, además de su desarrollo o ejecución. Es un trabajo de investigación sobre un tema específico, puede presentar diferentes niveles de profundidad y ser requisito para optar al título en estudios de pregrado y en las modalidades de especialización y maestría. No debe confundirse con la tesis.

Aunque la palabra monografía viene del latín monos (uno) y graphos (escrito), es empleada con distintos alcances. Umberto Eco, por ejemplo, en Cómo se hace una monografía se refiere a textos de 100 a 400 páginas redactados durante una carrera por una o varias personas, sobre un tema referido a los estudios profesionales del autor (Guerra 2007).

Una monografía puede ser definida como un documento que trata una temática en particular utilizando diversas fuentes compiladas y procesadas por uno o varios autores. La monografía generalmente tiene diversos puntos de vista sobre el tema trata- do, como también puede estar influenciada por las raíces culturales de su autor, logrando así una riqueza mayor (y claramente diferente) que si se tomara la información de una enciclopedia. Luego de rendir todos los exámenes correspondientes a la carrera, el estudiante presenta la monografía frente a un tribunal como un requisito necesario para obtener su título de especialista o magíster, no de doctor, porque para el doctorado se habla de tesis.

En general un artículo, un ensayo o una monografía de grado deben partir de la construcción de un plan de trabajo, el cual consta de tres partes complementarias ( $\mathrm{Zu}$ bizarreta. 1969: 57):

- El esquema del plan de trabajo, que consiste en un ordenamiento de los principales aspectos del tema que se investiga (capítulos) y de los aspectos secundarios de cada uno de ellos (subcapítulos), bajo un título perfectamente adecuado al tema-objetivo que se persigue en la investigación, lo cual quiere decir que responde, o debe responder, estrictamente a la realidad que tratamos de conocer y revelar. Por lo general, se añade a este esquema un lugar para la introducción al principio y otro al final para las conclusiones.

- La descripción del trabajo, que consiste en la explicación del esquema.

- Proposición de fuentes, métodos y procedimientos.

En un sentido amplio, la palabra monografía se usa para denominar los textos de trama argumentativa y función informativa que organizan, en forma analítica y crítica, datos sobre un tema recogidos en diferentes 
fuentes. Se diferencia del ensayo en que es más extensa, más profunda y debe estar completamente redactada en infinitivo e impersonal (no se dirá "yo opino", sino "es de precisar que". No se utilizan posesivos como nuestro país, nuestro sistema, etc., sino se usan los nombres propios) (Guerra, 2007).

\section{Tesis}

Es un documento escrito de carácter investigativo que solamente se usa en estudios de doctorado o Ph.D., aunque el término frecuentemente se le utiliza en especialización y maestría, lo cual es un error. Tesina y disertación son los pasos de una tesis doctoral, no se usa en otro nivel de estudio este término (Guerra 2007). Icontec la define como una disertación escrita mediante la cual el trabajo de investigación presenta un aporte significativo al conocimiento. Es requisito para optar al título de doctor.

\section{Conclusión}

La función más conocida de la escritura es la función comunicativa: se escribe para comunicar a otros algo que inicialmente es de uno; esto en la investigación tiene que ver con publicar, difundir. Además, a través de esta comunicación escrita, el que escribe empieza a promocionarse profesionalmente. Ambas funciones se logran a través de la escritura pública. Pero en la investigación también hay una escritura privada, y ella ocurre cuando el investigador escribe para sí mismo.

En cuanto a la justificación, en todos los campos del conocimiento las ideas científicas tienen que estar sostenidas y apoyadas por un aparato probatorio, aunque este modo probatorio varía de acuerdo con las disciplinas: no es lo mismo probar ideas en física que en historia o en educación. Cada comunidad discursiva tiene sus métodos de validación, y para publicar una investigación es preciso conocer no solo los métodos de validación empírica sino las formas como la respectiva disciplina argumenta por escrito sus afirmaciones. La lógica de la justificación no queda completada sino a través de la escritura pública. Al intentar publicar, es preciso convertir un trabajo de pensamiento privado en algo comunicable para otros.

Además de lo ya recomendado en el comienzo de este artículo sobre hacerse a una autodisciplina y un horario para escribir todos los días, hay que leer. Al ir leyendo hay que tomar apuntes de cada obra, con la referencia respectiva. Después de ello, comenzar con los diarios de observación y el ejercicio de armar el texto escrito con la estructura que se ha planteado.

Para superar los obstáculos de la escritura, concluyamos con Gabriela Carlino (2005), quien aporta algunos pasos importantes que permiten comenzar a escribir sin mayores problemas.

En primer lugar, es preciso subdividir la tarea, no pretender escribir privada y públicamente a la vez: hay que realizar primero mucha escritura privada y dejar la escritura pública para después. Sin olvidar que lo escrito ha de reescribirse teniendo presente al lector, aunque hay además que calcular los tiempos, porque esta reescritura es casi tan prolongada como la inicial.

En segundo lugar, gracias a que escribir en el mundo académico es una tarea que requiere muchas otras tareas, llamémoslo 
sub-tareas (por ejemplo, leer tomando nota, redactar ideas complejas, realizar trabajo obsesivo para mejorar y aumentar las referencias bibliográficas, etc.). Cuando una de estas sub-tareas llegue a paralizar la escritura, es conveniente variar la sub-tarea. Por ejemplo, tratando de escribir un marco teórico si después de varios días las páginas siguen en blanco, es necesario cambiar de tarea y empezar a teclear las referencias bibliográficas, lo cual consiste en un trabajo más mecánico pero que lleva su tiempo.

En tercer lugar, cuando se confrontan las páginas en blanco persistentes después de varios esfuerzos, también se puede hacer lo contrario de lo que se acaba de plasmar, y eso también ayuda. Es decir, a veces conviene sostener la tarea, no cambiarla. De la persistencia en el trabajo es de donde surgen las ideas; entonces cuando cuesta enfrentar la página en blanco, es aconsejable escribir sin control: sin censurar lo que uno escribe. Aflojarse sabiendo que eso que surja será "escritura privada", a la que ya habrá tiempo para convertir en pública. Entonces, dejar fluir ideas, sueltas, sin lógica aparente. Si no sale nada, el último recurso es escribir acerca de por qué cuesta escribir, escribir sobre los sentimientos que escribir despierta, escribir imaginando por qué uno está paralizado. Es decir, conviene no dejar de escribir.

En relación con esto, existe una sentencia clásica para enseñar a escribir, que aconseja Nulla die sine línea: "No dejes pasar un día sin escribir al menos una línea".

Para terminar, voy a hacer uso de las palabras del maestro Fernando Soto Aparicio cada vez que alguien va a solicitarle a su escritorio que le enseñe a escribir y le dé los principales secretos de las artes literarias: "no existen más que dos reglas para escribir: tener algo que decir y decirlo".

\section{Referencias}

Artiles Visbal, L. (1995, abril-junio). El artículo científico. Revista Cubana de Medicina General Integral.

Bergalli, R. y Rivera Beiras, I. (2006). Torturas y abuso de poder. Barcelona: Anthropos Editorial.

Betancur, M.C. (2000). Dichosos los que saben hablar. Bogotá: Editorial Plaza \& Janés.

Cano, C.A. (1999). La redacción del texto jurídico. Bogotá: Editorial Linotipia Bolívar y Cia S en C.

Carlino, G. (2005, 12 de noviembre). La importancia de la escritura en la investigación. Conferencia pronunciada en el Seminario Permanente de Investigación de la Maestría en Educación de la UDESA.

Clavo, J.L. (1996). Acercarse a la literatura. México: Longman Editores S.A.

Connelly y Clandinin. (1995). Relatos de experiencias e investigación narrativa. En Larrosa y otros. Déjame que te cuente. Ensayos sobre narrativa y educación. Barcelona: Laertes.

Díaz, A. (1999). Aproximación al texto escrito. Medellín: Universidad de Antioquia.

Finch Stoner, J.A., Freeman, E., Gilbert, D.R. y Mascaró Sacristán, P. (1996). Administración. Pearson Educación.

Fournier, C. (2006). Redacción I. México: Cengage Learning.

García, J.A. (2002). Historia de las mujeres en América Latina. Centro de Estudios la Mujer en la Historia de América Latina. Murcia, España: Universidad de Murcia.

García Márquez, G. (2007, 27 de abril). "Gabo, cien años de eternidad" 
(Discurso al cumplir 80 años: Homenaje en el V Congreso de la Lengua Española). El Tiempo, 2-5.

Gómez Fraile, F., Vilar Barrio, J.F., Tejero Monzón, M. (2002). Seis Sigma. Madrid: F C Editorial.

Gould Stephen, J. (1989). Wonderful Life: The Burgess Shale and the Nature of History. New York: W. W. Norton.

Guerra, Y. (2007). Investigar no es tan difícil como lo pintan. Bogotá: Carvajal.

Guerra, Y. (2007). Métodos en investigación. ¿Todos los caminos conducen a Roma? Bogotá: Carvajal.

Guerra, Y. (2008). Formación en investigación. Bogotá: Ciencia y Derecho.

Instituto Colombiano de Normas técnicas y Certificación (2008). NTC 1486. Documentación. Presentación de tesis, trabajos de grado y otros trabajos de investigación. Bogotá: ICONTEC.

Maqueo, A.M. (1988). Ortografía y redacción para secretarias. México: Limusa.

Marín, E. (2001). Los siete saberes necesarios para la educación del futuro. Bogotá: Cooperativa Editorial Magisterio.

Martínez y Martínez, R. (2007). Guía para organizar, escribir y editar un libro científico exitoso. México: El Manual Moderno.

Meza, J.L. (2008). Narración y pedagogía: elementos epistemológicos, antecedentes y desarrollos de la pedagogía narrativa. Revista Actualidades Pedagógicas, 51, 59-72.

Noguera, H. (2005). 100 Lecciones para aprendices de escritor. México: Panorama Editorial S.A.

Ontoria Peña, A R. y Gómez de Luque, Á. (2002). Aprender con mapas mentales: una estrategia para pensar y estudiar. Madrid: Narcea.
Ortega, W. (1994). Redacción y composición: técnicas y procedimientos. México: McGraw Hill.

O'Shaughnessy, J. (1991). Marketing competitivo. Madrid: Díaz de Santos.

Parra, M. (1994). Cómo se produce un texto escrito. Teoría y práctica. Bogotá: Cooperativa Editorial Magisterio.

Pérez Enríquez, R. (2010). Narrativa versus ciencia. México: CGEO - Universidad Nacional Autónoma de México.

Ramos, F. (2005). Pedagogía de la lectura en el aula. Guía para maestros. México: Editorial Trillas.

Reale G. y Antíseri, D. (2007). Historia de la filosofía. Bogotá: San Pablo.

Salazar, W.A. (2004). Alta redacción. Informes técnicos y administrativos. Bogotá: NET Educativa.

González, S., Varas Ibáñez, F., Villalba Pérez, J.C. y Cassagne. (2005). El derecho administrativo iberoamericano. Granada, España: Instituto Nacional de Administración Pública.

Serafini, M.T. (1985). Cómo redactar un tema. Didáctica de la escritura. Barcelona: Ediciones Paídos Ibérica S.A.

Serafini, M.T. (1990). Cómo se estudia. La organización del trabajo intelectual. Barcelona: Ediciones Paidós Ibérica, S.A.

Serafini, M.T. (1994). Cómo se escribe. Barcelona: Editorial Paidós Ibérica, S.A.

UNESCO. (1983). Guía para la redacción de artículos científicos destinados a la publicación (2a ed.). París: UNESCO.

Viramonte de Ávalos, M., Peronard, M. y Vásquez, M. (2000). Comprensión lectora: Dificultades estratégicas en resolución de preguntas inferenciales. Buenos Aires: Colihue. 
Wolcott, H. (2003). Mejorar la escritura de la investigación cualitativa. Medellín: Universidad de Antioquia.

Woo-Chong, K. \& Grepe, N. (1999). El mundo es tuyo pero tienes que ganártelo. México: Grupo Editorial Iberoamérica.
Zubizarreta, A. (1969). La aventura del trabajo intelectual (cómo estudiar y cómo investigar). Bogotá: Fondo Educativo Interamericano, S.A. 